\title{
OFICINAS PROBLEMATIZADORAS PARA O CUIDADO DE DIABÉTICOS INSULINODEPENDENTES NA ATENÇÃO BÁSICA EM SAÚDE
}

\author{
PROBLEM-BASED WORKSHOPS FOR THE CARE OF INSULIN DEPENDENT DIABETICS IN BASIC \\ HEALTH CARE
}

\author{
Daniela Goncalves Godoy Moutinho ${ }^{a^{*}}$, Maria Fernanda Petroli Frutuoso ${ }^{b^{* *}}$ \\ aenf.danimoutinho@yahoo.com.br, bfernanda.frutuoso@unifesp.br \\ * Secretaria Municipal de Saúde de Santos - Santos (SP), Brasil \\ **Universidade Federal de São Paulo - Santos (SP), Brasil
}

Data de recebimento do artigo: 24/07/2017

Data de aceite do artigo: 16/08/2017

\section{RESUMO}

Introdução: A atenção primária à saúde é lócus de estratégias de cuidado aos diabéticos insulinodependentes, incluindo os grupos de educação em saúde, com vistas a fortalecer o autocuidado. Objetivo: Descrever e analisar oficinas problematizadoras para diabéticos insulinodependentes atendidos em uma Unidade Básica de Saúde inserida em território vulnerável. Materiais e método: Trata-se de pesquisa-intervençấo com 14 diabéticos com média de idade de 62,5 anos. Foram organizados quatro encontros em formato de oficinas que se desdobraram a partir de temas geradores elencados nos primeiros encontros sobre as dificuldades do autocuidado. As transcriçóes dos encontros foram analisadas segundo técnica de análise de conteúdo. Resultados: As principais dificuldades no cuidado relatadas pelos diabéticos foram: a alimentação restritiva, a relação com os profissionais de saúde, a insulinoterapia e as questôes socioeconômicas. As estratégias utilizadas foram roda de conversa e degustação de alimentos. As oficinas proporcionaram abertura à experimentaçáo de sabores, como os edulcorantes, e aos diversos saberes, de modo que surgiram, no próprio grupo, formas de manejo para as dificuldades a partir do repertório dos participantes, do saber popular e do compartilhamento de estratégias de cuidado relacionadas ao território. Conclusóes: A utilização de oficinas para o cuidado de indivíduos diabéticos pode tornar o processo educativo mais horizontalizado, usando da troca de saberes e do manejo do cuidado a partir dos contextos do grupo e dos problemas enfrentados no cotidiano do indivíduo, da família, da comunidade e do território. Acredita-se que a intervenção que utiliza o compartilhamento de saberes torna-se potencializadora do autocuidado.

Palavras-chave: Educação em saúde; diabetes mellitus; atenção primária à saúde; autocuidado; alimentação.

\section{ABSTRACT}

Introduction: Primary health care is the locus of strategy for the care of insulin-dependent diabetics, including health education groups, aiming to strengthen self-care. Objectives: To describe and to analyze problem-based workshops conducted with insulin-dependent diabetics from a primary health care unit, located in a vulnerable neighborhood. Materials and methods: An intervention-research was conducted with 14 diabetics, with average age of 62.5 years. Four meetings were organized in the form of workshops, which unfolded from the generative themes listed in the first meeting, about the difficulties of self-care. All the meetings transcriptions were analyzed according to the content analysis technique. Results: According to the participants, the main difficulties of care were: restrictive diet, relationship with health care professionals, insulin therapy, and socioeconomic matters. The strategies used were round-table conversation and food tasting. The workshops provided an opportunity for experimentation of flavors, such as sweeteners, and for various types of knowledge, so that forms of management for the difficulties have arisen from the participants' repertoire, popular knowledge and sharing of care strategies related to the territory. Conclusions: The use of workshops for the care of diabetic individuals may make the educa- 
tional process more horizontal, starting from the exchange of knowledge and care management from the contexts of the group and from the problems faced in the daily life of individuals, family, community and territory. It is believed that the intervention which uses knowledge sharing becomes a potentiator of self-care.

Keywords: Health education; diabetes mellitus; primary health care; self-care; feeding.

\section{Introdução}

Dados epidemiológicos do Global Burden of Diseases, Injuries, and Risk Factors Study 2015 apontam que o diabetes é a sexta causa mais frequente de deficiências no mundo no período de 1990 a 2015, e que a mortalidade por diabetes mellitus (DM), em 195 países, cresceu $32,1 \%$ entre 2005 e 2015 , junto com os anos perdidos por morte prematura devido à doença e às patologias relacionadas ${ }^{1,2}$.

$\mathrm{O}$ aumento da prevalência de DM, associado ao aumento do número de indivíduos obesos, que oneram o sistema de saúde com tratamento de doenças e diversas complicaçóes, é um dos mais importantes desafios para os sistemas de saúde ${ }^{1}$.

O Ministério da Saúde brasileiro organizou o Plano de açôes estratégicas para o enfrentamento das doenças crônicas não transmissiveis no Brasil, 2011-2022, com compromissos de gestáo no enfrentamento das doenças crônicas não transmissíveis (cardiovasculares, câncer, respiratórias crônicas e diabetes) e seus fatores de risco modificáveis (tabagismo, consumo nocivo de álcool, inatividade física e alimentação inadequada). O Plano abrangeu três eixos estratégicos: vigilância, informação, avaliação e monitoramento; promoção da saúde; e cuidado integral ${ }^{3}$.

O contexto no qual medidas de prevenção de doenças e promoção de saúde podem reduzir significantemente a morbimortalidade por DM coloca foco na atenção básica em saúde, lócus responsável por açóes educativas de promoçấo de saúde para todos os grupos populacionais e para indivíduos com risco aumentado para desenvolvimento do DM; pela detecção precoce de diabéticos, por meio de exames de rotina; pelo suporte ao tratamento do diabético e à família, considerando insumos, monitoramento e açôes de educação em saúde, entre outras ${ }^{4}$.

Entre as dificuldades do manejo da DM estáo o controle alimentar, fundamental para a manutenção dos níveis glicêmicos adequados, evitando episódios de hipo e hiperglicemia, com grande risco de coma e morte. A aplicação da insulina exógena exige, ainda, orientação do diabético para ajustes de dosagem e autoaplicação do hormônio 5 . Essas dificuldades, especialmente entre os diabéticos insulinodependentes (DMID), colocam para os profissionais de saúde o desafio da produçáo de práticas educativas horizontalizadas, dialógicas e contextualizadas.
Essa concepção de educação em saúde dialoga com elementos do debate proposto por Paulo Freire sobre Educação Popular em Saúde (EPS), como a abertura para o diálogo entre profissional e usuário, desvencilhando-se da imagem vertical de cuidado; a politização a partir da corresponsabilização das ações a serem desenvolvidas em benefício da saúde individual e coletiva; o fomento à consciência crítica, com valorizaçáo da autonomia dos indivíduos atendidos ${ }^{6,7}$.

Gomes e Merhy ${ }^{8}$ consideram que a EPS busca a intensificação da participação popular a fim de maior democratização do sistema de saúde e da produçấo de cuidado a partir dos significados pessoais/coletivos, em uma relação recíproca de poderes e saberes entre profissionais e usuários.

Considerando a elevada prevalência de DM, as implicaçôes do autocuidado para o controle glicêmico e para a prevençáo de complicações, bem como o papel de capilaridade das açóes de promoção de saúde e prevenção de doenças que ocorrem na atenção básica à saúde, este artigo teve como objetivo descrever e analisar oficinas problematizadoras para diabéticos insulinodependentes atendidos em uma unidade básica de saúde de território vulnerável.

\section{Metodologia}

Trata-se de uma pesquisa-intervenção, delineada a partir da possibilidade de interação entre pesquisador e sujeito, em proporção igualitária, de maneira a permitir a troca contemplada no referencial teórico da EPS, bem como, promover interaçóes e refletir sobre a realidade dessa população? .

A pesquisa-intervenção permite uma atuação transformadora da realidade sociopolítica, conforme discutido por Rocha e Aguiar": "de ordem micropolítica na experiência social". Passos e Barros ${ }^{10}$ afirmam que: "neste contexto onde se atravessam clínica e política, pesquisa e açáo, a palavra intervenção se junta à pesquisa não para substituir a ação, mas para produzir outra relação entre teoria e prática, assim como entre sujeito e objeto".

Para a pesquisa, foi realizado levantamento de usuários DMID em uma Unidade Básica de Saúde (UBS), localizada na regiâo noroeste de Santos, SP. Utilizouse cadastro de insulinodependentes disponível na 
UBS, informaçóes sobre a retirada de insumos e sobre o Sistema Integrado de Saúde e Administração de Materiais (SISAM).

Os critérios de inclusão dos sujeitos na pesquisa foram: ser diabético insulinodependente; residir na área de abrangência da UBS; estar inscrito no Programa Hiperdia; retirar os insumos regularmente na UBS; ter disponibilidade para participar das oficinas.

A intervenção no formato de oficinas problematizadoras foi dividida em duas fases, a saber: oficinas de acolhimento e oficinas de intervenção. A proposta de oficinas problematizadoras favorece a discussão e produção cooperativa de meios de vida, distanciando-se das especialidades e hierarquias de saberes. Buscou-se desenvolver uma relação dinâmica entre pesquisador-pesquisado, determinando os caminhos da investigação à medida que os temas das oficinas emergiam dos encontros, considerando as demandas e singularidades do grupo.

As oficinas de acolhimento foram realizadas em três dias/períodos diferentes e visavam informar sobre a pesquisa, realizar a leitura e assinatura do termo de consentimento livre e esclarecido (aprovado pelo Comitê de Ética em Pesquisa da Universidade Federal de São Paulo, protocolo 727755 de 30/07/2014) e iniciar a intervenção a partir de uma pergunta norteadora "quais as principais dificuldades que você enfrenta no tratamento da DMID?" - a fim de estabelecer os temas geradores para a próxima fase.

Freire usa a expressão "temas geradores", que permite o diálogo entre o educador e o educando, para definição de um conteúdo programático que permite ao educador a percepção do outro como sujeito e possibilita estabelecer a troca de conhecimentos. Nesse sentido, as oficinas permitiram perceber o sujeito e seus "temas geradores", contribuindo para o fortalecimento do processo de cuidado na perspectiva da atenção básica à saúde ${ }^{7}$.

As oficinas de intervenção, quatro encontros agendados segundo a disponibilidade dos participantes, procuraram tratar dos temas gerados nos três encontros da primeira fase (Quadro 1).

Quadro 1: Descrição das oficinas sobre manejo do diabetes mellitus insulinodependente.

\begin{tabular}{|c|c|c|}
\hline Oficina & Tema & Objetivos \\
\hline A & $\begin{array}{l}\text { Alimentação e alte- } \\
\text { ração glicêmica }\end{array}$ & $\begin{array}{l}\text { - Relacionar a alimentação às alteraçóes } \\
\text { na glicemia; } \\
\text { - Relacionar os níveis glicêmicos aos } \\
\text { sintomas descritos nas primeiras } \\
\text { oficinas; } \\
\text { - Esclarecer dúvidas sobre a } \\
\text { alimentação. }\end{array}$ \\
\hline
\end{tabular}

$\mathrm{B}$

Alimentação e alteração glicêmica

- Relacionar a alimentação às alterações na glicemia;

- Relacionar os níveis glicêmicos aos sintomas descritos nas primeiras oficinas;

- Esclarecer dúvidas sobre a alimentação.

- Discutir o saber popular sobre alimen-

C Hábitos alimentatos e diabetes (uso de farinhas e água de quiabo, por exemplo); res e saber popular - Descrever os locais no território frequentados pelos DMID.

Alimentação,

D aspectos emocionais e alteraçóes glicêmicas
Estratégias

1. Vídeo ${ }^{11}$ sobre os alimentos que alteram a glicemia, mecanismo de ação da insulina e glicemia do diabético, apoio familiar;

2. Desenho do esquema da circulação sanguínea com o "trânsito" da glicemia e lesóes de órgãos alvo em lousa branca;

3. Demonstração, usando peças Lego ${ }^{\oplus}$, da quebra do carboidrato dentro do organismo;

4. Degustação de suco de laranja lima e mousse de mamão com aveia.

1. Demonstração da viscosidade do sangue usando seringa, agulha 30x7, óleo e água. Os participantes aspiravam na seringa o óleo e a água e desprezavam os dois em seguida, percebendo a diferença na resistência dos dois líquidos - analogia ao sangue hiperglicêmico no bombeamento cardíaco;

2. Desenho de esquema da circulação sanguínea com o "trânsito" da hiperglicemia e lesóes de órgáos alvo em lousa branca;

3. Demonstração, usando peças Lego ${ }^{\oplus}$, da quebra do carboidrato dentro do organismo;

4. Degustação de suco de laranja lima e mousse de mamão com aveia.

1. Roda de conversa sobre o saber leigo no tratamento do DMID;

2. Construção coletiva de mapa contendo os locais frequentados pelos participantes;

3. Diálogo com convidada DMID para compartilhar experiência com a doença;

4. Degustaçáo de brigadeiro e beijinho dietéticos.

1. Desenho dos grupos de alimentos em lousa branca;

2. Roda de conversa sobre a relação entre fatores emocionais e a DMID;

3. Diálogo sobre avaliação das oficinas;

4. Degustação de cocada e bolo de fubá dietéticos.

Fonte: Elaborado pelos autores, 2014 
Ainda que as datas e horários tenham sido pactuados coletivamente, os grupos foram heterogêneos, na medida em que alguns indivíduos faltaram em algumas datas e compareceram em outras. Nas oficinas de intervenção participaram treze DMID tipo 2 e um DMID tipo 1, número compatível com a estrutura física da UBS. Cada encontro teve duração de 45 a 60 minutos e o número de participantes variou de 3 a 8 , mais um moderador e um observador das áreas de enfermagem e nutrição.

As oficinas foram gravadas e o material transcrito foi analisado segundo técnica de análise de conteúdo, na qual são identificados núcleos de sentido presentes na comunicação, cuja frequência aponte para algo relacionado ao objetivo em análise ${ }^{12}$. Os resultados e discussão foram organizados de forma a descrever e problematizar as dificuldades do manejo do DMID, bem como o processo de construção das oficinas.

Quanto à identificação dos indivíduos, optou-se por não realizar a diferenciação dos autores das falas devido à dificuldade de identificação no momento de transcrição, especialmente nos momentos em que havia muitas falas simultâneas. Outra questão se refere à relevância da dinâmica coletiva do processo das oficinas, na qual os sujeitos traziam vivências singulares e compartilhavam não só questóes comuns, como também estratégias de manejo da doença.

\section{Resultados}

A realização das primeiras oficinas proporcionou o contato com a realidade dos participantes, e foram elencados como temas geradores: alimentação, aspectos socioeconômicos, insulinoterapia e relação profissional/ diabético. Também emergiram temas como a rede de apoio informal e saberes populares regionais.

Os temas relacionados à alimentação foram muito presentes e essa foi a dificuldade mais evidenciada pelos diabéticos. Os depoimentos apontam subtemas, como restrições alimentares: "a nutricionista cortou tudo. 'Fecha a boca, não vai tomar refrigerante, não vai poder comer bolo.' Nada!'; substituição de açúcar por edulcorante: "mandaram eu tomar café com aquele adoçante. Chorava!'; e questôes relacionadas à comensalidade: " $a$ minha mãe não vai em aniversário. Diz: eu não gosto, não como nada, não vou".

Nesse sentido, durante as oficinas, a estratégia de degustação possibilitou a experimentação de preparaçóes utilizando edulcorantes, que trouxeram relatos de surpresa e sobre a possibilidade de sua incorporação à dieta dos DMID: "gostoso. Não tem gosto de remédio", "é bom! Não tem gosto de coisa [adoçante] não".
Cabe ressaltar que essas falas apareceram após diversas reações verbais e não verbais relativas a dificuldades de adaptação ao sabor dos edulcorantes: "esse ai eu não quero nem... isso ai é horrivel!".

Além do sabor desagradável, o preço dos edulcorantes foi tema recorrente na descriçáo das dificuldades de compra dos alimentos prescritos para os DMID: "diz que esse aí [adoçante] é quase igual a açúcar. Mas é caro!".

Quanto aos aspectos socioeconômicos, relacionados ao território, foram apontadas dificuldades financeiras para a aquisição de alimentos prescritos: "entâo, pra gente seguir mesmo a dieta que eles pedem, eu mesmo não tenho condiçôes [financeiras] de seguir as dietas". Foi possível trabalhar essas dificuldades com a contribuição dos próprios participantes, a partir de falas como: "banana é fruta que eu mais como, a maçá é muito cara, eu como no lugar da maçã a [banana] prata".

Os momentos de degustação também propiciaram essa discussão, abordando os preços dos ingredientes e alternativas para adequar a dieta prescrita à realidade socioeconômica de cada um. Outra questão apontada foi a convivência familiar, expressa em algumas falas de apoio e em outras que apontam a dificuldade de articular os gostos dos membros da família e de manter a dieta hipoglicêmica, como:

minha filha mais velha entende mais do que os outros. Ela fica pegando muito no meu pé quando eu como alguma coisa que não é pra comer. Ela vive trazendo coisinha diet. às vezes as pessoas fala assim, a senhora faz bolo, faz... a senhora não come! Eles comem né, meu marido e minha filha.

Por outro lado, descrevem a dificuldade de cozinhar dois tipos de comida, considerando a existência de outros afazeres domésticos, em um contexto de destaque para o papel das mulheres na família:

eu comecei fazer comida pra todo mundo igual, mas minha filha e meu marido começaram a reclamar e não comiam. Eu tinha que fazer comida pra eles e fiquei cansada. Todos os afazeres que a gente tem, ainda tem que fazer dois tipos de comida.

Dentre as estratégias de enfrentamento da doença, evidenciaram-se os saberes regionais, como o uso de farinhas, água de cebola e água de quiabo (imersão de cebola/quiabo cortado em água filtrada por algumas horas para posterior ingestão): "a farinha de banana verde eu uso"; "a [farinha] de maracujá [...] é muito boa!"; "falam que é bom corta uma cebola, pôr na água e depois toma aquela água. Diz que é ótimo! Eu vi num programa de televisão"; "e o quiabo também". 
No discurso dos diabéticos também se nota o incômodo da aplicação das injeçóes diárias de insulina, que parece ser permeado por um possível conceito distorcido sobre seu efeito no organismo: "ela [insulina] deixa a gente, assim, parece que meio atrapalhada, muito lenta"; e sobre os efeitos desagradáveis após a aplicação da insulina: "aqui é o melhor lugar que tem pra aplicar, mas fica duro, parece que não enxerta direito, ficava uma massa por dentro".

A principal queixa quanto a insulinoterapia foi relativa à dor da picada de injeçâo e à picada da lanceta para o controle glicêmico, necessário ao usuário de insulina: "a picada da injeção!"; "que dói é furar o dedo... eu não furo que nem a doutora mandou fazer".

Também emergiu dessa discussão o fato de que muitas vezes os usuários recebiam agulhas específicas para obesos, o que nem sempre era necessário e acarretava mais dor na aplicação das injeçóes. Outra questão importante referente à insulinoterapia é salientada neste depoimento: "tem umas ali que às vezes os números são diferentes [graduação da seringa em ml ou UI]".

As oficinas propiciaram a troca de informaçóes a respeito dos melhores locais para aplicação de insulina e tipos de agulha e seringa, partindo da perspectiva dos próprios participantes, conforme o diálogo a seguir:

Nessa semana eu peguei uma grande e tive observando, não é necessário enfiar a agulha toda, coloca a metade da agutha e injeta o líquido.

Eu aplico desse lado e aplico desse outro aqui também. Agora, na perna dói demais.

É bom inverter sempre. Não fazer só num espaço. Faz aqui, faz aqui.

Além da interação entre os participantes explicitada neste diálogo, o caráter de processual de intervenção dos encontros se fez claro, no sentido de sanar dúvidas, foi a abordagem sobre o exame de hemoglobina glicada, relatado pela participante como "diabete glicada" e que, em sua perspectiva, seria uma condição para aplicação de insulina regular: "[insulina] regular pra quem tem a glicada também. Diabete glicada".

Dificuldades relacionadas ao contato com o profissional também apareceram: ("ele [médico] meteu medo"). Diversos depoimentos durante as oficinas apontam para insuficiência do cuidado, segundo os diabéticos, tanto na atenção básica: ("só mede e manda pra casa repousar, não faz nada"), como no pronto atendimento: ("uma vez também eu fui no pronto-socorro e não fizeram nada').

Em relação ao grupo estudado, a avaliação das oficinas foi positiva: "gostei de tudo", "muitas coisas que a gente não sabia", "é sempre uma novidade, uma coisa a aprender mais". Outro aspecto evidenciado no processo de pesquisa foi a dificuldade de monitoramento e vigilância dos usuários diabéticos. A pesquisa-intervenção identificou, a princípio, 291 fichas de usuários cadastrados na UBS como insulinodependentes. Destas, apenas 126 estavam atualizadas e com regularidade na retirada de insumos.

\section{Discussão}

No processo de construção das açôes, as oficinas A e $\mathrm{B}$ abordaram o mesmo tema usando estratégias diferentes, após avaliação do primeiro encontro $(\mathrm{A})$. Ainda que a abordagem tenha sido avaliada como acessível aos diabéticos, o vídeo foi pouco disparador de diálogo e reflexōes, possivelmente em decorrência das usuais abordagens mais verticalizadas. Durante as oficinas, a construção de conduta profissional mais dialógica e menos impositiva foi ocorrendo gradualmente.

Ainda que as primeiras oficinas tenham se debruçado sobre a pergunta norteadora com o intuito de obter elementos para a proposta dos encontros seguintes, diversos mecanismos de enfrentamento da doença e do controle da glicemia foram relatados pelos participantes em todas as reunióes, além de peculiaridades relacionadas ao território. Nesse sentido, o conteúdo das conversas nas oficinas trouxe, a todo o momento, relatos de dificuldades e formas de manejo relacionadas à doença.

A restrição alimentar evidenciada nas falas dos participantes os coloca em um lugar diferenciado no contexto social. Esse aspecto foi discutido por Silva et al. ${ }^{13} \mathrm{em}$ estudo de seguimento com diabéticos e/ou hipertensos que aponta que a dieta restritiva traz conflitos constantes para o indivíduo, pois repercute no prazer da comensalidade, nos relacionamentos sociais e na própria percepção das necessidades do corpo.

Ribeiro et al. ${ }^{14}$ apontam dificuldades dos profissionais de saúde em orientar um plano alimentar exequível, além das prescriçóes relacionadas a uma alimentação possível somente em um mundo ideal. Nesse sentido, o manejo alimentar foi explorado na discussão sobre o aumento glicêmico relacionado aos grupos alimentares, com ênfase nos carboidratos e, entre estes, o açúcar, bem como naquela sobre o papel das fibras no controle da glicemia. A estratégia de degustação de preparaçóes durante os encontros abriu espaço para abordar as dificuldades e dúvidas e ofereceu, in loco, estratégias de manejo a partir do repertório alimentar dos participantes.

Assim, nessa proposta educativa, foram incluídos doces típicos brasileiros (cocada, bolo de fubá), comumente consumidos em festas infantis (beijinho e brigadeiro) e uma preparação não habitual na dieta do brasileiro (mousse de mamão), todos feitos substituindo-se 
açúcar por adoçante e utilizando gêneros alimentícios facilmente encontrados no comércio da região e que fossem de baixo custo.

O contexto socioeconômico sobressaiu-se em alguns momentos, convergindo com estudo de Souza ${ }^{15}$, em que a situação econômica das famílias e suas atividades diárias interferem no manejo da doença. Assim como no estudo em questáo, procurou-se abordar os temas pensando em acesso para essas populaçóes, como no caso dos momentos de degustação em que os participantes trocavam informaçóes sobre os preços dos produtos.

Os participantes também colocaram em evidência dificuldades e potencialidades com relação ao apoio familiar. Algumas falas evidenciaram que os familiares incentivavam o cuidado dos diabéticos, e outras demonstraram a ausência de compreensão da família de adequar-se a hábitos alimentares mais saudáveis. Houve maior recorrência do segundo caso quando se tratava de máes e esposas, considerando que a tarefa de cuidar da família e da alimentação era atribuição exclusiva da mulher.

Souza ${ }^{15}$ descreve a importância das relaçóes de gênero na rotina do cuidar e do cuidar-se, retratando o entendimento do papel da mulher como provedora do cuidado a partir da percepção de que, biologicamente, essa função é da mulher que dá à luz e cuida desde o nascimento. Diversos autores apontam a importância do apoio familiar para o cuidado do DMID ${ }^{15-17}$.

Em outro momento os participantes indicaram o uso de alternativas em prol do autocuidado, como o uso das farinhas, da água de quiabo e da água de cebola. A utilização de alimentos não convencionais com finalidade terapêutica é bastante difundida nas classes populares. Gomes e Merhy ${ }^{8}$ consideram que:

a postura do profissional de saúde para com a medicina popular deveria ser de respeito e diálogo, identificando e apontando situaçóes de que se tem conhecimento de malefícios causados à populaçáo por algumas técnicas e medicamentos populares, mas valorizando as práticas que representam uma sistematização de conhecimentos que vão se acumulando ao longo de várias geraçôes.

A abordagem desses temas foi pautada na valorização do saber popular como estratégia adicional ao uso da insulina e ao manejo alimentar, uma vez que o controle glicêmico é importante para a prevenção de complicaçóes e que muitas estratégias valorizadas popularmente necessitam ser melhor estudadas. $\mathrm{Na}$ abordagem sobre os alimentos usados para controle glicêmico segundo o saber popular, retomou-se o papel das fibras no controle da glicemia para melhor entendimento e valorização do uso de farinhas na dieta.
O diálogo entre os saberes popular e científico é um dos pilares da EPS. Segundo Freire, para que se estabeleça um diálogo a fim de um agir comum, nenhum dos lados pode perder a humildade, ou seja, nenhum saber se sobrepóe ${ }^{7}$.

Sobre a dificuldade de autoaplicação de insulina ficou evidente que se dá pela dor da picada de injeção. Silva et al. ${ }^{13}$ apontaram que, entre os diabéticos, há o reconhecimento da necessidade de aplicação de insulina, citada como "sagrada". Todavia, existem conflitos internos relacionados à agressão ao corpo pela injeção rotineira, aos compromissos com horários e à imagem da autoaplicação na presença de amigos e familiares ${ }^{13}$. Souza e Zanetti ${ }^{18}$ descrevem como complicações cutâneas locais da aplicaçáo de insulina o eritema (vermelhidão no local de aplicação), variações na estrutura lipídica do tecido subcutâneo (formação de massas palpáveis, de gordura e tecido fibroso, ou mesmo de lesóes de fundo imunológico), além de nódulos e hematomas relacionados a trauma pela agulha.

Quanto às dificuldades da insulinoterapia, apesar de doloridas, as injeçóes subcutâneas rotineiras, para esse público, são essenciais para a manutenção da vida e para diminuição de sequelas em longo prazo. Nessa perspectiva, a intervençáo procurou relacionar o uso da insulina ao processo metabólico necessário para o controle glicêmico, reforçando o custo-benefício do uso do fármaco e abordando o tamanho da agulha de insulina disponível na UBS, dado que muitas vezes os usuários recebiam agulhas específicas para obesos, o que nem sempre era necessário.

A questáo da dor da picada de injeção converge com os achados de Hayes et al. ${ }^{19}$, que indicaram sentimentos de medo, dor e lesão corporal, e de Khan et al. ${ }^{20}$ que identificaram fobia de receber as injeçôes diariamente, também relacionada à dor.

As trocas de experiências relacionadas a insulinoterapia proporcionaram melhor reconhecimento dos sujeitos como atores importantes no processo de autocuidado.

$\mathrm{O}$ relato que descreve mudança na graduação das seringas anuncia uma questão para os profissionais da UBS, na medida em que as seringas que estavam sendo entregues não possuíam a graduaçáo em unidade internacional, podendo dificultar a autoaplicação, uma vez que muitos usuários podem se confundir ao realizar a conversão e assim usar dosagens incorretas, prejudicando o controle glicêmico.

Outras dificuldades apontadas na literatura, relacionadas ao uso de insulina, não apareceram no grupo estudado, como a aplicação de injeção em público e a necessidade de adequar horários de refeição para não sofrer efeitos indesejáveis do hormônio, a dependência 
dos horários e do auxílio de outras pessoas na aplicação da injeção, bem como a percepção dos sinais de hipoglicemia ${ }^{19,20}$.

Aproveitou-se o tema da hemoglobina glicada (citada por um participante como "diabete glicada") para esclarecimento da necessidade desse exame e para a explicação do porquê de ele ser solicitado. Este consiste em um exame de sangue que detecta a ligação de glicose a hemoglobina para diagnóstico de diabetes e de pré-diabetes e também para controle da eficácia do tratamento/ controle dos níveis glicêmicos. Quanto maior a glicemia sanguínea, em longo prazo, maior será o percentual de ligação entre glicose e hemoglobina ${ }^{21}$.

Percebeu-se fragilidade no vínculo entre usuários e profissionais de saúde em algumas falas em que o profissional aparece como negligente ou como alguém que estabelece relações hierárquicas. Ribeiro et al. ${ }^{22}$ afirmam que a redução do distanciamento é um desafio para profissionais e serviços e que se deve encontrar práticas mais próximas às realidades dos indivíduos atendidos.

Ribeiro et al. ${ }^{14}$ descrevem que esse distanciamento e a relação verticalizada, traduzida na prescrição de tratamentos, de condutas e de comportamentos, podem ser desencadeadores de descrença no serviço/atendimento, porém deve-se considerar o conjunto da acessibilidade, das políticas públicas, dos conceitos de saúde, das classes sociais, entre outros. Para Zamzam et al. ${ }^{17}$, o distanciamento entre profissional e usuário é uma das barreiras para a melhora clínica, apontando a indiferença dos médicos com relaçáo à gravidade da doença e ao tempo de consulta muito limitado, bem como é uma barreira a percepção, por parte dos usuários, de que o enfermeiro não tem capacidade de sanar dúvidas e de que os médicos não entendem as dificuldades no manejo da doença.

Nesse sentido, as oficinas permitiram o resgate do espaço de escuta e do fortalecimento de vínculo, um conceito-ferramenta para o melhor desempenho da atenção básica nos territórios. Intervir sobre a relação profissional-usuário constitui um desafio que depende de um processo de aproximação e abertura entre os envolvidos. Em busca da melhoria do vínculo, as oficinas propiciaram espaço para construção de estratégias de cuidado para além das prescriçóes estabelecidas, comumente, nos atendimentos individuais.

Tomando o cuidado do DMID na atenção básica, destacam-se as oficinas problematizadoras como estratégia educativa. Moreno et al. consideram que a educação em saúde desenvolvida em grupos tem potencial para estabelecer redes de apoio, o que pode favorecer a aprendizagem e a incorporação de práticas de saúde efetivas construídas a partir do diálogo ${ }^{23}$.

Adolfsson et al. ${ }^{24}$, em estudo comparativo entre aconselhamento individual e grupos de educação (empowerment groups) para diabéticos tipo 2, evidenciaram que as açóes em grupo, que partiram da identificaçáo de problemas com enfoque no diálogo dos participantes para obtençáo de alternativas e consensos no tratamento, resultaram em indivíduos mais ativos e comprometidos, bem como em uma relação profissional-paciente mais horizontalizada.

Há que se empenhar alguma energia na criação de grupos de educação em saúde, como demanda toda proposta de modificação de rotinas. É necessário que o profissional envolvido esteja engajado com a proposta e possa balizar o conhecimento científico, o saber popular e a experiência do próprio grupo.

Dias et al. ${ }^{25}$ consideram necessário preparar a equipe para a abordagem horizontalizada, para as intervençôes e o manejo dos conteúdos e para promover o processo emancipatório. Por outro lado, a partir da experiência nessa pesquisa, depreendeu-se que a constituição e a manutenção de um grupo passam por questôes que envolvem a disponibilidade tanto de profissionais como de usuários, a logística do serviço, o tempo de duração dos encontros e o espaço físico do local.

Outro aspecto relevante em relaçáo ao cuidado de DMID na atenção básica é o olhar interdisciplinar sobre o manejo da doença. Para o grupo estudado, questóes relacionadas à alimentação foram as mais frequentes, o que evidencia a importância da complementariedade dos saberes e a relevância de profissionais de diversas formaçóes para o manejo tanto das oficinas como das estratégias de autocuidado.

Pimentel et al. ${ }^{26}$, em estudo realizado com profissionais de cinco municípios brasileiros, apontam dificuldades para oferta de ações de alimentação e nutrição na atenção básica em saúde, diante da falta de condiçóes de infraestrutura e do despreparo dos profissionais, não nutricionistas, para abordagens envolvendo a comida e o comer. Atualmente, há poucos nutricionistas inseridos na atenção primária à saúde do município estudado, e os que compóem o quadro de profissionais nesse nível de atenção têm disponibilidade restrita para desenvolver açôes nas unidades, pois trabalham em forma de rodízio em equipamentos de uma mesma regiáo.

Há, no município, a aposta na transformação de unidades de atenção básica organizadas pelo modelo tradicional em Unidades da Estratégia Saúde da Família e na criação de Núcleos de Apoio à Saúde da Família. Entretanto, para a unidade estudada, que tem a maior área de abrangência da cidade, a mudança poderá ocorrer somente a longo prazo, considerando a necessidade de construção de nova unidade de saúde para reorganização do território.

Ainda, pode-se considerar que, à medida que surgem novos temas ou demandas no grupo, outros 
profissionais poderiam se aproximar pontualmente das atividades (psicólogos, educadores físicos, farmacêuticos etc.).

$\mathrm{Na}$ proposta apresentada, as oficinas permitiram a apreensão da realidade individual e local, a partir da questão disparadora, e a troca de experiências cotidianas no enfrentamento à doença, fortalecendo a possibilidade de participação ativa no processo de discussão e a inclusão de conhecimentos científicos relacionados à DM de maneira horizontal.

Segundo Dias et al..$^{25}$, insere-se no processo de planejamento das açóes em grupo a possibilidade de realização e alcance dos objetivos, bem como a sua avaliação pelos participantes. Em relação ao grupo estudado, a avaliação das oficinas foi positiva, o que pode evidenciar que há interesse em novos grupos e/ou estratégias de cuidado, bem como a potencialidade do dispositivo grupal no cuidado de DMID no contexto em questão.

Por fim, pontua-se a vigilância em saúde como uma questão que emergiu nesta proposta. Segundo Faria e Araújo ${ }^{27}$, a vigilância em saúde permite a organização dos serviços valendo-se do conhecimento de características do território, das condiçóes de vida e saúde da população, que incluem cultura, politização, acesso à educação e aos serviços de saúde, que podem orientar a gestão para organizaçáo dos serviços, bem como para o atendimento das demandas populacionais.

A pesquisa-intervenção identificou ainda grande número de inscritos no programa Hiperdia e elevada proporção de DMID não monitorados. Várias são as dificuldades cotidianas para consolidação e fortalecimento da vigilância desse grupo, entre as quais encontram-se os recursos humanos limitados, muitas vezes não condizentes com a demanda da UBS; a baixa adesão da equipe no manejo dos programas, relacionada muitas vezes a não significação da tarefa; a dificuldade de acompanhar um território e populaçáo dinâmicos, especialmente na região das palafitas, pela rotatividade de pessoas; bem como a grande área de abrangência da UBS estudada.

\section{Conclusão}

As oficinas problematizadoras propiciaram a discussão de dificuldades no manejo do controle glicêmico, que incluíram a alimentação restritiva, a relação com os profissionais de saúde, a insulinoterapia e as questóes socioeconômicas. A metodologia das oficinas possibilitou o uso de diversas estratégias, tornando o processo educativo mais horizontalizado, potencializando a troca de saberes e a construçáo de possibilidades de cuidado a partir dos contextos do indivíduo, da família, da comunidade e do território. Extrapolando os limites da pesquisa, houve modificação das práticas profissionais, disparada por encontros conduzidos de forma compartilhada e a partir de reflexôes constantes sobre educação em saúde, diabetes e oficinas problematizadoras.

\section{Referências}

1. GBD 2015 Disease and Injury Incidence and Prevalece Collaborators. Global, regional and national incidence, prevalence, and years lived with disability for $310 \mathrm{di}-$ seases and injures, 1990-2015: a systemic analisys for the Global Burden and Disease study 2015. The Lancet. 2016;388:1545-602.

2. GBD 2015 Mortality and Causes of Death Collaborators. Global, regional, and national life expectancy, all-cause mortality, and cause-specific mortality for 249 causes of death, 1980-2015: a systemic analysis for the Global Burden of Disease Study 2015. The Lancet. 2016;388:1459-544.

3. Malta DC, Oliveira TP, Santos MAS, Andrade SSCA, Silva MMA. Avanços do Plano de Açóes Estratégicas para o Enfrentamento das Doenças Crônicas Não Transmissíveis no Brasil, 2011-2015. Epidemiol Serv Saude. 2016;25(2):373-90.

4. Brasil. Ministério da Saúde. Secretaria de Atenção à Saúde. Departamento de Atenção Básica. Diabetes mellitus. Brasília, DF: Ministério da Saúde; 2006 [citado em 2017 jul 24]. 56 p. Disponível em: https://goo.gl/aSgiWM

5. Sociedade Brasileira de Diabetes. Diretrizes da Sociedade Brasileira de Diabetes 2013-2014 [Internet]. São Paulo: AC Farmacêutica; 2014 [citado em 2015 ago 20]. 382 p. Disponível em: https://goo.gl/jfgo5

6. Freire P. Pedagogia da autonomia: saberes necessários à prática educativa. 39a ed. São Paulo: Paz e Terra; 2009. 146 p.

7. Freire P. Pedagogia do oprimido. $58^{\mathrm{a}}$ ed. São Paulo: Paz e Terra; 2014. 253 p.

8. Gomes LB, Merhy EE. Compreendendo a educação popular em saúde: um estudo na literatura brasileira. Cad Saúde Pública. 2011;27(1):7-18.

9. Rocha ML; Aguiar KF. Pesquisa-intervenção e a produção de novas análises. Psicol Ciênc Prof. 2003;23(4):64-73.

10. Passos E, Barros RB. A construção do plano da clínica e o conceito de transdisciplinaridade. Psic Teor e Pesq [Internet]. 2000;16(1):71-9.

11. Novartis. Conhecendo o diabetes mellitus com o "Dr. Legalvus" [Internet]. São Paulo: Novartis; 2014 [citado em 2014 jul 29]. Vídeo: 9 min, 28 seg. Disponível em: https:// youtu.be/IW4R9I6AG4Q

12. Minayo MCS. O desafio do conhecimento: pesquisa qualitativa em saúde. 12a ed. São Paulo: Hucitec; 2010.

13. Silva TR, Feldmam C, Lima MHA, Nobre MRC, Domingues RZL. Controle de diabetes mellitus e hipertensão arterial com grupos de intervenção educacional e 
terapêutica em seguimento ambulatorial de uma Unidade Básica de Saúde. Saúde e Soc. 2006;15(3): 180-9.

14. Ribeiro AG, Cotta RMM, Ribeiro SMR, Dias CMGC, Araújo RMA. Representaçóes sociais de mulheres portadoras de hipertensão arterial sobre sua enfermidade: desatando os nós da lacuna da adesão ao tratamento na agenda da saúde da família. Physis. 2011;21(1):87-112.

15. Souza AC. Cartografias do cuidado de indivíduos com diabetes mellitus em situação de pobreza [Tese]. Porto Alegre: Universidade Federal do Rio Grande do Sul; 2011.

16. Carbone ET, Rosal MC, Torres MI, Goins KV, Bermudez OI. Diabetes self-management: perspectives of Latino patients and their health care providers. Patient Educ Couns. 2007;66(2):202-10.

17. Zamzam S, Anoosheh M, Ahmadi F. Barriers to diabetes control from Syrian women's perspectives. Jpn J Nurs Sci. 2013;10(1):121-9.

18. Souza CR, Zanetti ML. Administração de insulina: uma abordagem fundamental na educação em diabetes. Rev Esc Enferm USP. 2000;34(3):264-70.

19. Hayes RP, Bowman L, Monahan PO, Marrero DG, McHorney CA. Understanding diabetes medications from the perspective of patients with type 2 diabetes: prerequisite to medication concordance. Diabetes Educ. 2006;32(3):404-14.

20. Khan H, Lasker SS, Chowdhury TA. Prevalence and reasons for insulin refusal in Bangladeshi patients with poorly controlled type 2 diabetes in East London. Diabet Med. 2008;25(9):1108-11.
21. Sociedade Brasileira de Diabetes [Internet]. São Paulo: SBD; c2017 [atualizado em 2014 abr 29; citado em 2015 ago 20]. O teste de hemoglobina glicada (A1C): O que é e para que serve. Disponível em: https://goo.gl/nF8ugT

22. Ribas CRP, Santos MA, Zanetti ACG, Zanetti ML. Representaçóes sociais de pacientes com diabetes mellitus sobre o atendimento por profissionais de saúde. Psico PUCRS. 2013;44(1):139-49.

23. Moreno DMFC, Visani I, Ruiz MRAR, Muller L, Bittencourt JC, Pelicioni AF. Avaliação das açóes de promoção de saúde em hipertensão e diabetes em três unidades básicas de saúde no município de São Paulo. In: Caderno técnico CAEPS-DANT: capacitação em avaliação da efetividade das ações de promoção da saúde em doenças e agravos não transmissíveis. São Paulo: Prefeitura do Município de São Paulo; 2009. p. 23-5.

24. Adolfsson ET, Starrin B, Smide B, Wikblad K. Type 2 diabetic patients' experiences of two different educational approaches - a qualitative study. Int J Nurs Stud. 2008;45(7):986-94.

25. Dias VP, Silveira DT, Witt RR. Educação em saúde: o trabalho de grupos em atenção primária. Rev APS. 2009;12(2):221-7.

26. Pimentel VRM, Sousa MF, Hamann EM, Mendonça AVM. Food and nutrition in the Family Health Strategy in five Brazilian cities. Cien Saude Colet. 2014;19(1):49-57.

27. Faria HX, Araujo MD. Uma perspectiva de análise sobre o processo de trabalho em saúde: produção do cuidado e produção de sujeitos. Saúde Soc. 2010;19(2):429-39.

\section{Como citar este artigo:}

Moutinho DGG, Frutuoso MFP. Oficinas problematizadoras para o cuidado de diabéticos insulinodependentes na atenção básica em saúde. Rev. Aten. Saúde. 2017;15(54):74-82. 